\title{
Metabolic Control in Type 1 Diabetes: Is Adjunctive Therapy the Way Forward?
}

Harriet Warnes · Rebecca Helliwell - Sam Matthew Pearson •

Ramzi A. Ajjan

Received: July 12, 2018 / Published online: September 12, 2018

(C) The Author(s) 2018

\section{ABSTRACT}

Despite advances in insulin therapies, patients with type 1 diabetes (T1DM) have a shorter life span due to hyperglycaemia-induced vascular disease and hypoglycaemic complications secondary to insulin therapy. Restricting therapy for T1DM to insulin replacement is perhaps an over-simplistic approach, and we focus in this work on reviewing the role of adjuvant therapy in this population. Current data suggest that adding metformin to insulin therapy in T1DM temporarily lowers HbA1c and reduces weight and insulin requirements, but this treatment fails to show a longer-term glycaemic benefit. Agents in the sodium glucose co-transporter-2 inhibitor (SGLT-2) class demonstrate the greatest promise in correcting hyperglycaemia, but

Enhanced Digital Features To view enhanced digital features for this article go to https://doi.org/10.6084/ m9.figshare.6979601.

H. Warnes · R. Helliwell · S. M. Pearson - R. A. Ajjan School of Medical Sciences, The University of Leeds, Leeds, UK

S. M. Pearson · R. A. Ajjan

Department of Diabetes and Endocrinology, The Leeds Teaching Hospitals NHS Trust, Leeds, UK

R. A. Ajjan ( $\square)$

The Leeds Institute of Cardiovascular and Metabolic Medicine, Leeds, UK

e-mail: r.ajjan@leeds.ac.uk there are safety concerns in relation to the risk of diabetic ketoacidosis. Glucagon-like peptide1 agonists (GLP-1) show a modest effect on glycaemia, if any, but significantly reduce weight, which may make them suitable for use in overweight T1DM patients. Treatment with pramlintide is not widely available worldwide, although there is evidence to indicate that this agent reduces both HbA1c and weight in T1DM. A criticism of adjuvant studies is the heavy reliance on HbA1c as the primary endpoint while generally ignoring other glycaemic parameters. Moreover, vascular risk markers and measures of insulin resistance-important considerations in individuals with a longer T1DM duration-are yet to be fully investigated following adjuvant therapies. Finally, studies to date have made the assumption that T1DM patients are a homogeneous group of individuals who respond similarly to adjuvant therapies, which is unlikely to be the case. Future longerterm adjuvant studies investigating different glycaemic parameters, surrogate vascular markers and harder clinical outcomes will refine our understanding of the roles of such therapies in various subgroups of T1DM patients.

Keywords: DPP-4 inhibitors; GLP-1 analogues; Hypoglycaemia agents; Metformin; Pramlintide; SGLT2 inhibitors; Type 1 diabetes (T1DM) 


\section{INTRODUCTION}

It has long been known that type 1 diabetes mellitus (T1DM) is associated with an increased incidence of adverse vascular events, and that these cardiovascular events occur at a younger age than in the nondiabetic population [1]. Despite advances in therapy, the rate of end organ damage in T1DM remains high, and mortality is significantly increased compared to individuals without diabetes. The National Institute for Health and Care Excellence (NICE) in the United Kingdom recommends that patients should aim to achieve a glycated haemoglobin (HbA1c) below $48 \mathrm{mmol} / \mathrm{mol}$ unless they are troubled by recurrent hypoglycaemia, in which case individualised targets should be agreed on a patient-by-patient basis [2]. Similarly, the American Diabetes Association recommends $\mathrm{HbA} 1 \mathrm{c}<7 \% \quad(53 \mathrm{mmol} / \mathrm{mol})$ in T1DM patients, with a lower level of $6.5 \%$ ( $48 \mathrm{mmol} / \mathrm{mol})$ in selected individuals [3]. The current standard treatment predominantly involves intensive insulin regimes that aim to lower HbA1c in order to reduce the risk of microvascular disease and limit long-term macrovascular complications $[4,5]$.

A key aim in these patients is the reduction of macrovascular events, but the relationship between glycaemic control and vascular occlusive disease is far more complex than initially envisaged. The DCCT-EDIC trial has shown that lowering HbA1c reduces the long-term risk of myocardial infarction [6]. However, intensively treating glycaemia predisposes to hypoglycaemia, which in itself increases the risk of vascular events [7]. Mechanisms for hypoglycaemia-induced vascular damage include the induction of an inflammatory and prothrombotic milieu due to low glucose levels [8]. To further complicate matters, large fluctuations in glucose control, typically seen in individuals with inadequate insulin dosing, are also thought to be associated with vascular damage through increased oxidative stress and an enhanced inflammatory response [9]. Our understanding of the mechanistic pathways linking glucose variability with increased cardiovascular risk is incomplete and causality has yet to be fully proven, but the evidence behind this being a contributory factor in the development of cardiovascular disease (CVD) is growing [10].

In addition to the detrimental effects of hypoglycaemia, the weight gain associated with insulin treatment predisposes to insulin resistance, which promotes vascular damage through the induction of endothelial dysfunction and predisposition to an inflammatory and prothrombotic environment [11]. This explains the failure of some HbA1c-focussed studies in T1DM to demonstrate significant associations between this glycaemic marker and adverse vascular events, instead suggesting that insulin resistance may play a stronger role in the development of these complications $[12,13]$.

Weight gain has been implicated in increased insulin resistance, and this is a wellestablished mechanism underlying the pathogenesis of type 2 diabetes mellitus (T2DM) [14]. Therefore, T1DM patients who are overweight can develop insulin resistance, giving rise to the 'double diabetes' (DD) phenotype. The definition of DD is yet to be formalised and is currently used as a loose term to describe overweight T1DM patients, particularly in the presence of increased insulin requirements. Previous work has shown that patients with T1DM are particularly prone to weight gain, with one large prospective study demonstrating a sevenfold increase in the rate of obesity in T1DM over a follow-up period of 18 years as compared with the general population [15]. Other studies have confirmed the increased prevalence of obesity in T1DM [16], raising the question as to whether adjuvant medications should be considered in these patients to reduce weight irrespective of changes in markers of glycaemic control. Moreover, evidence suggests that overweight T1DM patients are at higher risk of vascular complications compared with their lean counterparts [17], further highlighting the need for alternative, non-insulin-based therapies in these individuals.

The current review assesses the role of adjuvant non-insulin-based therapies in T1DM in relation to improving glycaemia, controlling weight and modulating the risk of vascular complications of diabetes. We have conducted a 
PubMed search of articles using the terms 'type 1 diabetes' and 'metformin', 'sodium glucose co-transporter-2 inhibitors (SGLT2)' (and each member of this family), 'glucagon like peptide-1 agonists (GLP-1)' (and each member of this family), 'amylin' (and 'pramlintide') and 'dipeptidyl peptidae-4 inhibitors (DPP4)' (and each member of the family) up to June 2018, and attempted to summarise the major trials for each class.

This article is based on previously conducted clinical trials and does not contain unpublished work with human participants or animals performed by any of the authors.

\section{METFORMIN}

Metformin, a biguanide agent, has been used for the treatment of T2DM for over half a century. Its exact mode of action is not entirely clear, but it is believed to inhibit production of hepatic glucose, reduce intestinal glucose absorption and improve glucose uptake and utilisation [18]. The use of metformin in T1DM has been repeatedly suggested, with some studies-but not all-showing improved glycaemic control, assessed as a reduction in HbA1c.

One of the largest studies is the recent randomised controlled REMOVAL trial, which involved 428 T1DM patients. The study investigated the role of metformin in modulating carotid intima media thickness (cIMT) in those above the age of 40 years with multiple cardiovascular risk factors [19]. Metformin had no significant effect on cIMT, although a decrease in HbA1c 3 months after the introduction of metformin $(-0.24 \%, p=0.0001)$ was demonstrated, which was not sustained at study end (3 years). A much smaller trial involving 15 T1DM patients with an average body mass index (BMI) of $31.3 \mathrm{~kg} / \mathrm{m}^{2}$ reported a decrease in HbA1c of $0.8 \%(p<0.005)$ after 16 weeks of metformin treatment compared to placebo [20]. Similarly, a significant reduction in HbA1c of $(0.6 \%)$ (DCCT-aligned) was observed in a trial of 114 patients over 6 months compared to placebo $(+0.2 \%)$ (DCCT-aligned) $(p<0.001)[21]$. No significant difference in $\mathrm{HbA} 1 \mathrm{c}$ was reported in trials with durations of 24 weeks to 1 year, involving 24-100 overweight patients with HbA1c $>7 \%$ [22-24]. Similarly, a recent metaanalysis of 13 trials did not identify enough evidence to suggest HbA1c is significantly lowered by adjuvant metformin [25].

While the effects of metformin on glycaemia appear to be short term and unsustained, a reduction in daily insulin dose has been reported in several trials when metformin was added to standard therapy. In a 16-week trial involving 15 overweight patients, a significant decrease in insulin dose by 10 units/day was reported [20]. Similarly, a 24-week trial involving 24 overweight patients reported a significant reduction in daily insulin dose of 8.8 units/day [22]. Another larger trial with a duration of 1 year, comprising 100 T1DM patients with poor glycaemic control (HbA1c $>8.5 \%)$ and an average BMI of $26.2 \mathrm{~kg} / \mathrm{m}^{2}$, reported a decrease of 5.7 units/day in insulin dose compared with placebo [24]. Moreover, a trial of 114 patients over 6 months also identified a reduction of 0.04 units $/ \mathrm{kg}$ compared to placebo (0.02 units/ $\mathrm{kg}, p=0.004)$ [21]. Additional small trials reported nonsignificant decreases in the total daily insulin dose [23]. Taken together, these data suggest a general reduction in insulin dose after the introduction of metformin, but longterm studies are lacking. REMOVAL was one of the longest and largest studies of the use of metformin in T1DM, and this showed an initial reduction in total daily insulin requirement which was not sustained at 3 years [19].

Multiple studies involving overweight patients provide evidence of significant weight loss associated with metformin use for up to 3 years [19, 21-24]. A recent meta-analysis of 13 trials identified the same outcome, with a reduction in BMI of $-1.14 \mathrm{~kg} / \mathrm{m}^{2}(-2.05$ to $-0.24, p=0.01$ ) [25]. Others failed to corroborate these findings, although these were generally small studies conducted over 8-16 weeks and involving no more than 24 patients each $[20,26]$. A recent retrospective study of 181 patients who were taking metformin or standard therapy found no significant difference in weight over 10 years of follow-up [27]. Of note, the groups were not evenly matched, with those taking metformin having a significantly increased BMI compared to those not taking 
metformin at study onset $\left(29.8 \mathrm{vs} 28.6 \mathrm{~kg} / \mathrm{m}^{2}\right.$; $p<0.01$ ). Confounders such as diet and physical exercise were not included in analysis. The retrospective design of the study and the fact that the groups were not evenly matched at study onset make it challenging to draw conclusions about the ability of metformin to reduce weight in those with T1DM over longer time periods.

Metformin is not known to cause hypoglycaemia as it does not stimulate endogenous insulin secretion; however, in insulin-treated patients it can theoretically increase the risk of low glucose levels [18]. A meta-analysis of 13 trials involving 1,183 patients identified an increased hypoglycaemic risk with adjuvant metformin (1.23, CI 1.00-1.52, $p=0.05)$ [25]. The REMOVAL trial involving 387 patients reported 0.16 severe hypoglycaemic events per patient per year, which was similar to the control arm [19]. Another trial uncovered 58 events of severe hypoglycaemia in 49 patients over a 1-year period [24] in metformin-treated T1DM patients, but this was not significantly different from the placebo group $(p=0.261)$. Finally, another trial identified no statistical difference between 114 patients taking adjuvant metformin and the placebo group $(p=0.2)$ [21].

Overall, metformin reduces HbA1c initially, but this effect does not appear to be sustained. Also, metformin reduces daily insulin doses, but again this reduction is not seen over longer periods of follow-up. Metformin-related weight loss is perhaps more sustained, but long-term conclusive data are lacking. Metformin does not appear to increase the rate of severe hypoglycaemic events, although the role of this agent in contributing to milder hypoglycaemia is unclear and will require continuous glucose monitoring studies.

A summary of the main studies of metformin in T1DM is provided in Table 1.

\section{SGLT2 INHIBITORS}

Sodium glucose co-transporter type 2 mediates the reabsorption of glucose in the renal tubule, so inhibiting this co-transporter results in glycosuria and reduces blood glucose levels [28].
Moreover, this is associated with weight loss and reduced blood pressure, further helping individuals with T2DM and the metabolic syndrome. It should be noted that SGLT2 inhibitors are currently only licenced for use in individuals with T2DM; their use in T1DM patients is limited to research studies, or they may be applied by specialists outside licensed indications.

Small-scale and short-duration studies have shown that SGLT2 inhibitors can be effective at reducing HbA1c in T1DM. One study enrolled 75 participants with HbA1c between 58 and $91 \mathrm{mmol} / \mathrm{mol}$ and BMI between 18.5 and $35 \mathrm{~kg} /$ $\mathrm{m}^{2}$. Individuals were randomly assigned in a 1:1:1:1 fashion to empagliflozin $2.5 \mathrm{mg}, 10 \mathrm{mg}$, $25 \mathrm{mg}$ or placebo for 28 days in addition to their standard multiple daily injection (MDI) insulin regimens [29]. At 28 days there was a significant difference in HbA1c between those on empagliflozin and the placebo group (a difference that showed a dose-dependent response). Another study (albeit single-armed) looked at the introduction of $25 \mathrm{mg}$ empagliflozin to standard insulin therapy in 40 participants with T1DM [30]. The study was intended as a proof of concept and found a significant reduction in HbA1c from baseline $(8.0 \pm 0.9 \%$ to $7.6 \pm 0.9 \% ; p<0.0001)$, associated with significant decreases in weight, waist circumference and total daily insulin dose. Similarly, dapagliflozin at $10 \mathrm{mg} /$ day significantly reduced HbA1c from baseline in 12 overweight patients with poorly controlled T1DM over a 24 -week study period $\quad(9.18 \pm 1.02 \% \quad$ to $8.05 \pm 1.09 \%$; $p=0.0156$ ) [31]. Sotagliflozin (a dual SGLT1 and SGLT2 inhibitor) also caused a significant reduction in $\mathrm{HbA} 1 \mathrm{c}$ in 33 patients with T1DM who had an average BMI of $26.6 \mathrm{~kg} / \mathrm{m}^{2}$ $(-0.55 \%, p=0.002)$ [32]. Additionally, a recent RCT involving 1402 patients with an average HbA1c of $8.26 \%$ reported there was a significantly greater reduction in HbA1c with sotagliflozin compared to placebo after 24 weeks of treatment $(-0.79 \%,-0.33 \%$ respectively, $p<0.001)$ [33].

A recent RCT involving 351 patients on MDI or CSII insulin therapy trialled the addition of 100 or $300 \mathrm{mg}$ canagliflozin as adjuvant therapy. All patients had T1DM, and the range of BMI for the group was $21-35 \mathrm{~kg} / \mathrm{m}^{2}$. At the 


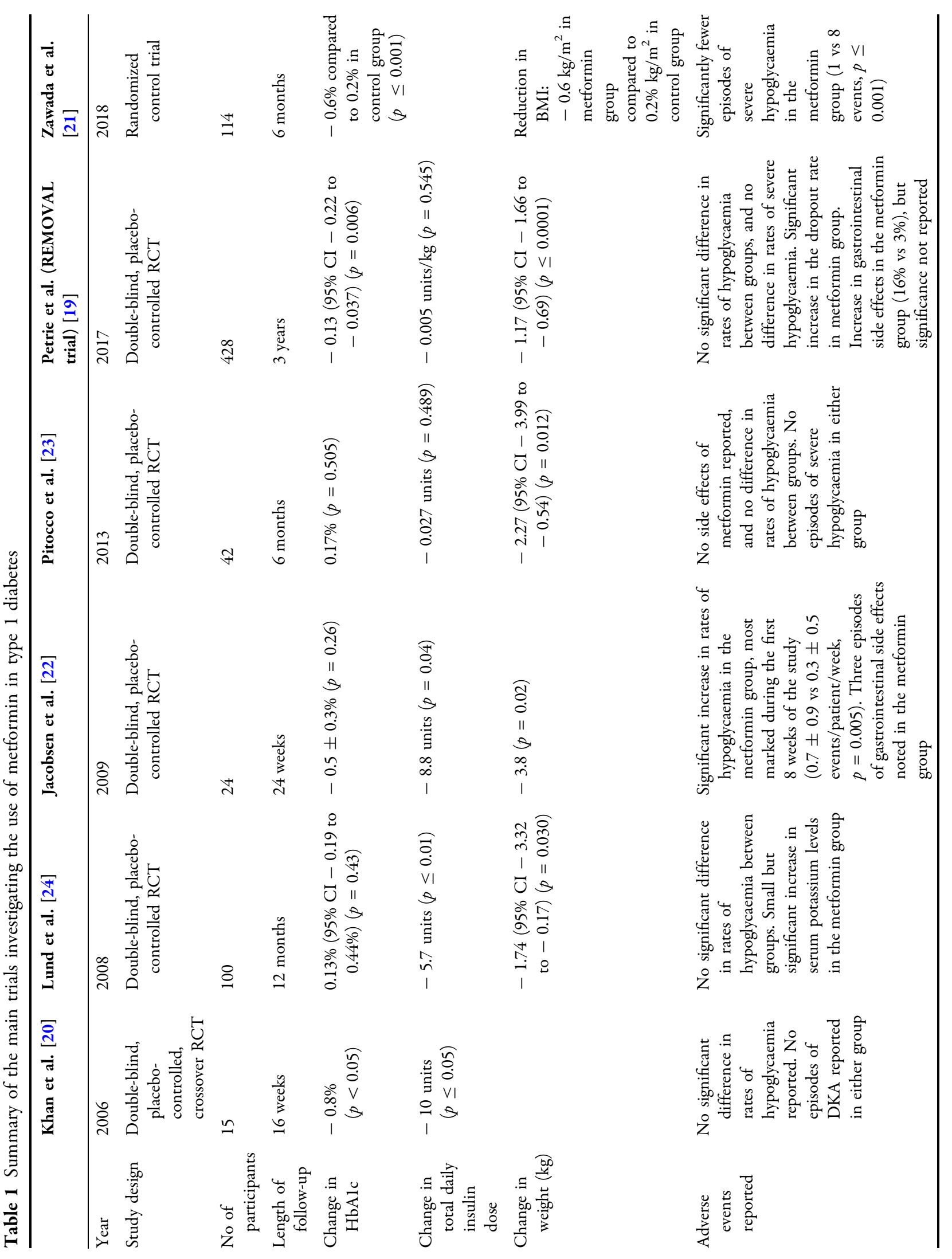


study endpoint, 18 weeks, those taking canagliflozin at either dose presented a significant reduction in HbA1c compared to placebo. This was not accompanied by weight gain in either group [34]. Other findings of the study were that there were similar rates of hypoglycaemia across the groups, and that there was an increased numerical rate in female genital mycotic infections in those taking $300 \mathrm{mg}$ canagliflozin compared to placebo $(21.2 \%$ vs 5.6\%). A further important finding was an increase in diabetic ketoacidosis (DKA) in those taking canagliflozin compared to placebo (4.3\%, $6.0 \%, 0 \%$ for $100 \mathrm{mg}, 300 \mathrm{mg}$ and placebo, respectively).

An additional recent RCT of 833 patients with T1DM and poor glycaemic control (HbA1c $61-97 \mathrm{mmol} / \mathrm{mol}$ ) studied adjuvant dapagliflozin at $5 \mathrm{mg} /$ day and $10 \mathrm{mg} /$ day [35]. Adjuvant dapagliflozin was associated with a significantly decreased HbA1c versus placebo at $5 \mathrm{mg} /$ day and $10 \mathrm{mg} /$ day $(-0.42 \%, p<0.0001$; $-0.45 \%, p<0.0001$, respectively). This effect was established at week 4 and maintained for the study duration of 24 weeks. Moreover, a reduction in body weight of $-2.96 \%$ $(p<0.001)$ at $5 \mathrm{mg} /$ day and $-3.72 \%$ $(p<0.0001)$ at $10 \mathrm{mg} /$ day was observed. This effect was established by week 8 and maintained throughout the study. More genital infections were reported in the study group compared to the placebo group (11\% for $5 \mathrm{mg} /$ day, $12 \%$ for $10 \mathrm{mg}$ /day vs $3 \%$ for placebo), but a statistical analysis was not reported. Similar rates of hypoglycaemia were observed among the trial groups. Moreover, there was no statistically significant difference in definite DKA between the three study arms ( $1 \%$ for $5 \mathrm{mg} /$ day, $2 \%$ for $10 \mathrm{mg} /$ day and $1 \%$ for placebo).

Whilst SGLT2 inhibitors are known to reduce glycaemia, they may also be useful as weight loss medications. A trial of sotagliflozin, a combined SGLT1 and SGLT2 inhibitor, observed a significant reduction in body weight of 33 patients with an average starting BMI of $26.6 \mathrm{~kg} / \mathrm{m}^{2}(-1.7 \mathrm{~kg}, p<0.01)$ [32]. Similarly, an RCT involving 1402 patients with an average baseline BMI of $28.29 \mathrm{~kg} / \mathrm{m}^{2}$ reported a significant difference in weight loss between the sotagliflozin and control groups $(-2.98 \mathrm{~kg}$, $p<0.001$ ), with an average loss of $2.21 \mathrm{~kg}$ in the sotagliflozin group and an average weight gain of $0.77 \mathrm{~kg}$ in the control group [32]. Additionally, a trial of 40 patients with various starting BMIs $\left(18.5-35 \mathrm{~kg} / \mathrm{m}^{2}\right)$ identified a $3.5 \%$ reduction in body weight after 8 weeks of $25 \mathrm{mg}$ empagliflozin, although this was not a placebocontrolled trial [30]. A trial of $100 \mathrm{mg}$ and $300 \mathrm{mg}$ canagliflozin in patients with BMI $21-35 \mathrm{~kg} / \mathrm{m}^{2}$ did show a weight reduction, but its significance was undetermined $(-3.1 \%$ and $-5.1 \%$, respectively) [34]. Therefore, further research is required to determine whether the potent weight-loss effects of SGLT2 inhibitors observed in patients with T2DM translate to the T1DM population, as this may highlight a new target group for these agents [36].

Due to the mechanism of action of SGLT2 inhibitors, hypoglycaemia is not common in those with T2DM [37]. A meta-analysis of trials looking at the use of SGLT2 inhibitors in those with type $1 \mathrm{DM}$ did not find a significantly different rate of hypoglycaemia compared to placebo [38].

Changes in insulin requirements have been reported in some trials investigating the addition of SGLT2 inhibitors to insulin monotherapy in type 1 diabetes. One large trial with 1402 participants which studied the addition of sotagliflozin (a dual SGLT1 and SGLT2 inhibitor) found significant reductions in placebocorrected total daily insulin dose, bolus insulin dose and basal insulin dose $(-9.7 \%,-12.3 \%$ and $-9.9 \%$, respectively, $p \leq 0.001$ for all) [33]. A recent meta-analysis reported reductions in both bolus and basal insulin doses when a SGLT2 inhibitor was added to insulin monotherapy ( -3.6 units/day, 95\% CI -2.0 to -5.3 , and -4.2 units/day, $95 \%$ CI -2.2 to -6.3 , respectively) [39]. There is therefore good evidence that adding a SGLT2 inhibitor reduces the insulin requirement in those with type 1 diabetes, and there appears to be reduction in both basal and bolus insulin doses for those on multiple daily injection regimens.

A systematic review and meta-analysis of trials using SGLT2 inhibitors in addition to insulin in T1DM found significant improvements in fasting glucose, HbA1c, weight and total daily insulin dose in those treated with 
these medications [38]. However, the systematic review also highlighted an increased incidence of diabetic ketoacidosis (DKA) in patients taking adjuvant SGLT2 inhibitors versus placebo, identifying 16 cases of DKA in 581 patients. The review did note that the studies reported both mild hyperglycaemic and normoglycaemic DKA as well as typical DKA. Rates of other adverse events such as hypoglycaemia were not different from placebo. This provides evidence that this drug class is beneficial in those with type 1 diabetes, but the number of trials that met the search criteria $(n=10)$ was small. A subsequent systematic review and meta-analysis including 14 trials published similar results [39]. Significant reductions in $\mathrm{HbA1c}$ were documented at 0.4\% [95\% confidence interval (CI) 0.35, 0.46; $p<0.001]$, as well as significant reductions in weight, systolic blood pressure, and total daily insulin dose, accompanied by a reduction in glucose variability assessed using continuous glucose monitoring (CGM). Note that the authors also reported significant increases in DKA and genital tract infections when compared to placebo (OR 3.38 and 3.44, respectively).

The EMPA-REG study pointed to a significant decrease in mortality from cardiovascular causes in T2DM patients taking empagliflozin compared to placebo [40]. A meta-analysis of studies looking at cardiovascular outcomes in those taking SGLT2 inhibitors and suffering from T2DM highlighted significant reductions in allcause mortality as well as mortality from cardiovascular causes [41]. Direct comparisons between these study groups of T2DM and T1DM patients cannot be drawn, but nevertheless, this drug class shows promising results in reducing adverse cardiovascular outcomes in those with impaired glucose metabolism.

In summary, there is early evidence to support the use of SGLT2 inhibitors as an adjuvant therapy in patients with T1DM, as there is an observed reduction in HbA1c without an increased risk of severe hypoglycaemia. However, future studies are required with more comprehensive glycaemic assessment using continuous glucose monitoring, which will help to fully establish the glycaemic benefits of this class of drugs. Moreover, outcome studies are required to ascertain the role of these drugs in reducing microvascular and macrovascular complications in T1DM, as well as to further answer specific concerns with regards to rates of DKA and genital tract infections in patients taking this class of medication.

A summary of the main studies of the use of SGLT2 inhibitors in T1DM is provided in Table 2.

\section{GLP-1 RECEPTOR AGONISTS}

The key effects of GLP-1 receptor agonists are that they slow gastric emptying (thus reducing appetite), enhance pancreatic insulin secretion and suppress pancreatic glucagon secretion. These effects work to maintain glucose homeostasis in patients with T2DM [42]. Studies regarding gastric emptying in type 1 diabetes with GLP-1 analogues are relatively scarce, but there is some evidence to suggest that this effect is not observed in this group [43].

Despite the predicted beneficial glycaemic effects of GLP-1 receptor agonists in T2DM, a number of recent clinical studies have generally failed to show an impact of GLP-1 analogues on HbA1c when used in addition to insulin therapy in T1DM [44-47]. However, a retrospective study of exenatide involving a limited number of patients $(n=11)$ reported a significant reduction in $\mathrm{HbA1c}$ from baseline $(7.7 \%)$ to 3 months of treatment $(7.1 \%)(p=0.013)$ [48]. Note that all of the patients studied in this retrospective analysis were treated with continuous subcutaneous insulin infusion (CSII). A 6-month trial of exenatide in 13 patients with HbA1c $<8.4 \%$ found a significant decrease in postprandial plasma glucose compared to placebo, suggesting a potential reduction in glycaemic variability [47]. Moreover, the bolus insulin dose was significantly reduced by GLP-1 receptor agonists in a number of studies [44, 46-48].

Therefore, there is significant interstudy variability in the results obtained with this class of drugs in terms of their ability to improve glycaemic control in T1DM. A meta-analysis of 7 studies ( $n=206$ participants) has shown a modest HbA1c reduction caused by the use of 


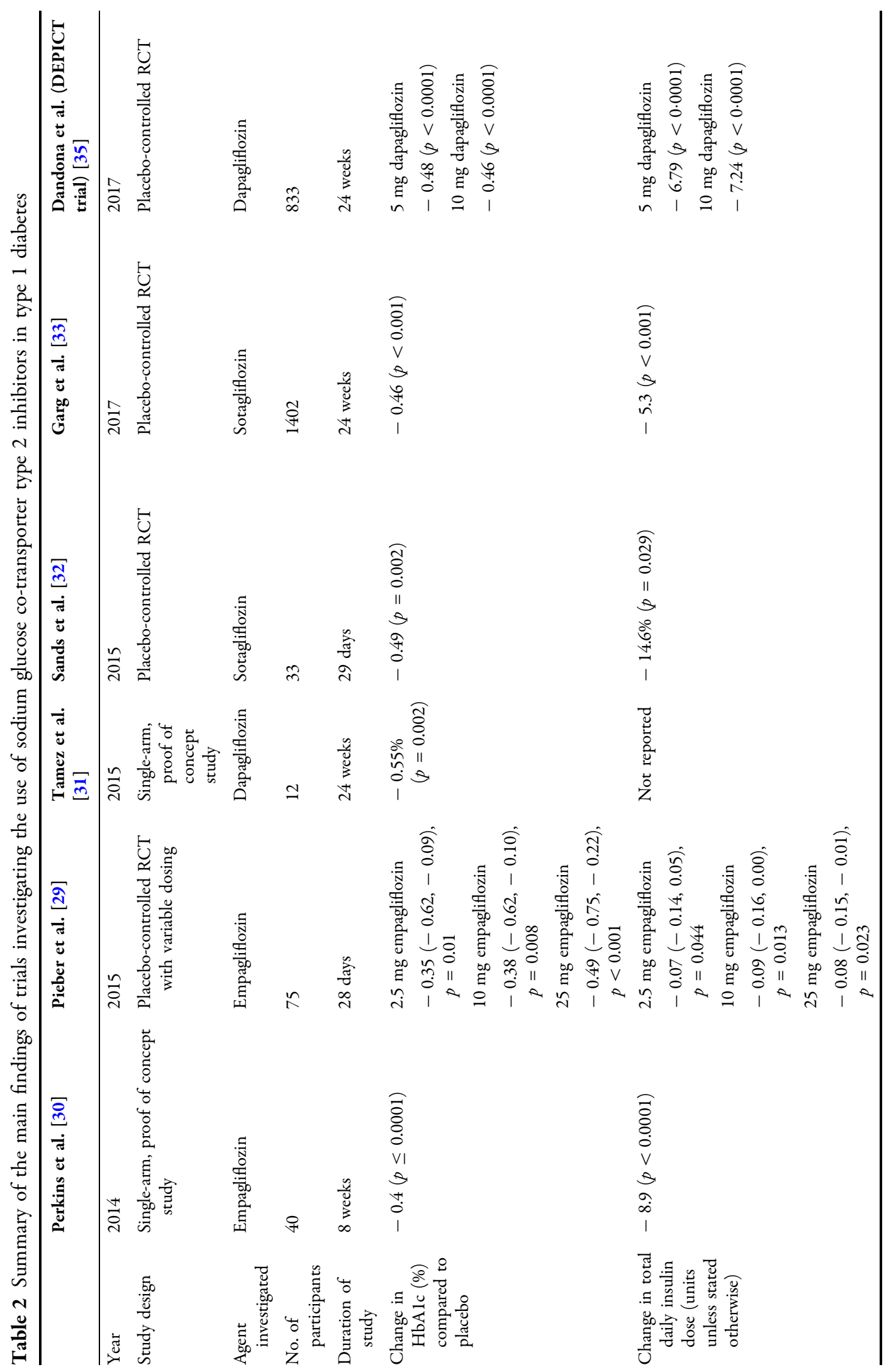




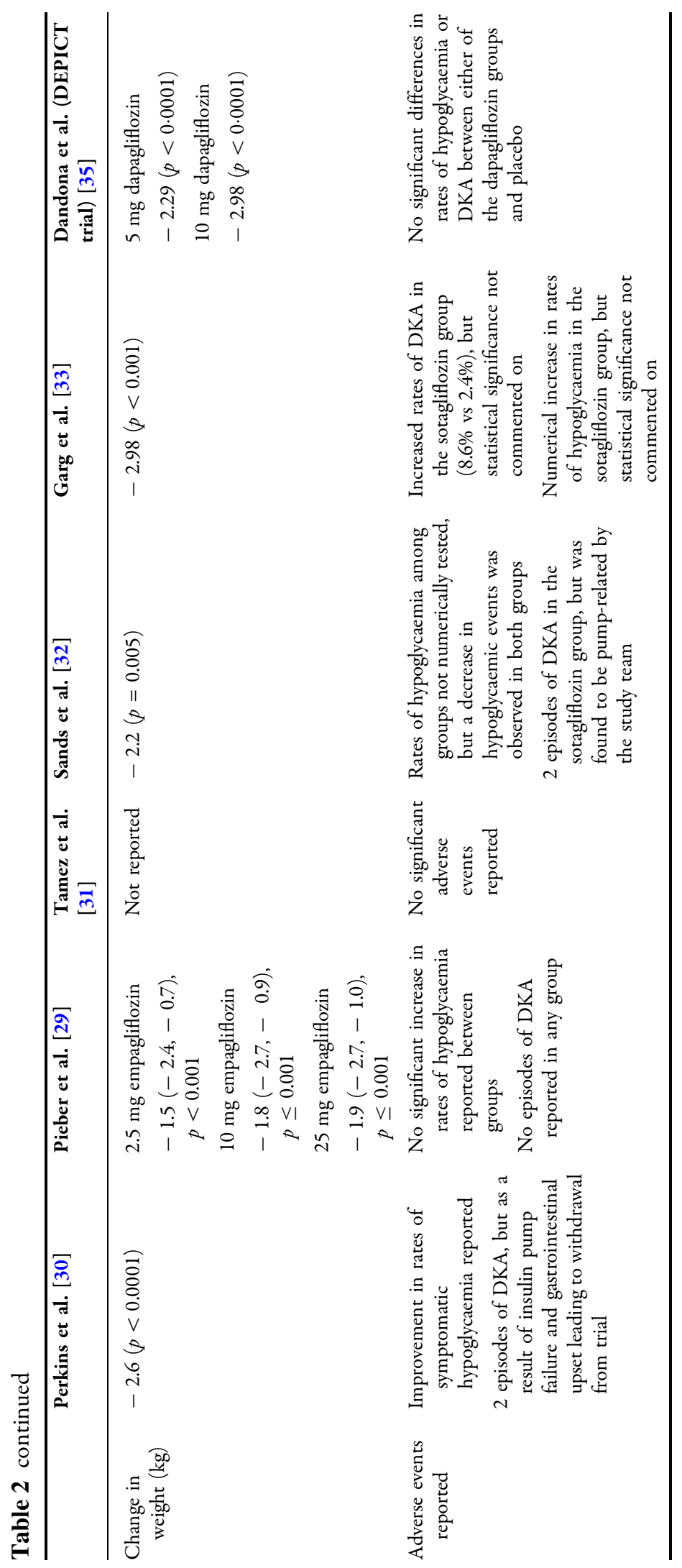


GLP-1 analogues in T1DM $(-0.21 \%, p<0.03)$, which was associated with a reduction in the total daily weight-adjusted bolus insulin dose $(-0.06 \mu / \mathrm{kg}, 95 \% \mathrm{CI}-0.1$ to $0.02, p<0.001)$, whereas the total daily insulin was not significantly lower than in the placebo group [49].

In general, GLP-1 analogues have shown promise in their ability to reduce the weight of T1DM patients. Studies reported weight losses of between 4.2 and $6.8 \mathrm{~kg}$ compared to placebo over 12-52 weeks in healthy-weight and overweight patients [44-48].

A study analysing additional measures of body fat in overweight patients found a decrease in waist circumference of $3.3 \mathrm{~cm}$ $(p=0.002)$ and a decrease in total adipose tissue (measured by computed tomography) of $61 \mathrm{~cm}^{2}$ compared to placebo $(p=0.0001)$ [45]. Additionally, a 6-month retrospective study of exenatide in overweight patients with HbA1c $<8.4 \%$ measured insulin sensitivity using the hyperinsulinaemic-euglycaemic clamp method and reported an increase in insulin sensitivity of $1.94 \mathrm{mg} / \mathrm{m}^{2} / \mathrm{min}$ per $\mu \mathrm{U} /$ $\mathrm{mL}(p=-0.0039)$ [47]. A 24-week RCT of liraglutide in overweight patients with HbA1c $<8.5 \%$, however, found no significant difference in insulin sensitivity [45]. Possible explanations for this discrepancy in outcome may be related to differences in study design and patient population, the limited number of subjects enrolled, or it may represent a genuine difference between the two agents studied.

Many trials involving GLP-1 receptor agonists have reported no significant difference in incidence or rate of hypoglycaemic events $[45,46,48]$, although one study involving 40 overweight T1DM patients has shown a decrease in hypoglycaemic events (incidence rate ratio 0.82 , 95\% CI 0.74-0.90) with GLP-1 analogue therapy [44].

The largest RCTs published on this topic are the ADJUNCT ONE and ADJUNCT TWO studies. ADJUNCT ONE recruited 1398 adults with T1DM to receive liraglutide (at varying doses) or placebo in a 3:1 randomisation with insulin being adjusted in a treat-to-target manner over 52 weeks [50]. Despite the treat-to-target design, there was a numerical decrease in HbA1c across all three doses of liraglutide at 52 weeks
(0.6 mg/1.2 mg/1.8 mg daily), but only the reduction seen with the $1.2 \mathrm{mg}$ daily dose was statistically significant vs placebo $(-0.15 \%, 95 \%$ CI -0.27 to $-0.03, p=0.0164)$. A statistically significant reduction in weight was observed across all liraglutide doses, and total daily insulin dose was also reduced in the 1.8 and $1.2 \mathrm{mg}$ liraglutide groups vs placebo. Of concern, rates of symptomatic hypoglycaemia were increased in all liraglutide groups vs placebo, and there was a significant increase in hyperglycaemia with ketosis in those treated with $1.8 \mathrm{mg}$ liraglutide daily in addition to insulin. ADJUNCT TWO ran for 26 weeks and recruited 835 subjects [51]. Similarly to ADJUNCT ONE, participants were randomised to liraglutide $0.6 \mathrm{mg} / 1.2 \mathrm{mg} / 1.8 \mathrm{mg}$ daily or placebo in a $3: 1$ manner. In contrast to the aforementioned study, changes in insulin dosing were capped. A statistically significant reduction in $\mathrm{HbA1c}$ was observed for all liragutide groups vs placebo, coupled with reductions in weight and insulin requirements. However, rates of symptomatic hypoglycaemia were increased in the liraglutide $1.2 \mathrm{mg}$ group (21.3 vs. 16.6 events/patient/year; $p=0.03)$, and rates of hyperglycaemia with ketosis $(>1.5 \mathrm{mmol} / \mathrm{L})$ were increased in those treated with $1.8 \mathrm{~m}$ /day of liraglutide (0.5 vs. 0.1 events/patient/year in liraglutide and placebo groups, respectively; $p=0.01$ ).

Pancreatitis is a feared consequence of GLP-1 RAs in T2DM. Rates of this event have varied among studies in T2DM patients, but none of the studies reviewed for this article reported pancreatitis as an adverse event. Long-term follow-up studies will be required to ensure safety in T1DM.

A summary of the main studies of GLP-1 analogues in T1DM is provided in Table 3.

\section{PRAMLINTIDE}

Amylin is a polypeptide co-secreted from pancreatic $\beta$-cells [52]. Having first been identified in 1987 , there has been a great deal of research into this hormone and its effects on metabolism, particularly in the first decade of the twenty-first century. Due to autoimmune destruction of pancreatic beta cells in type 1 


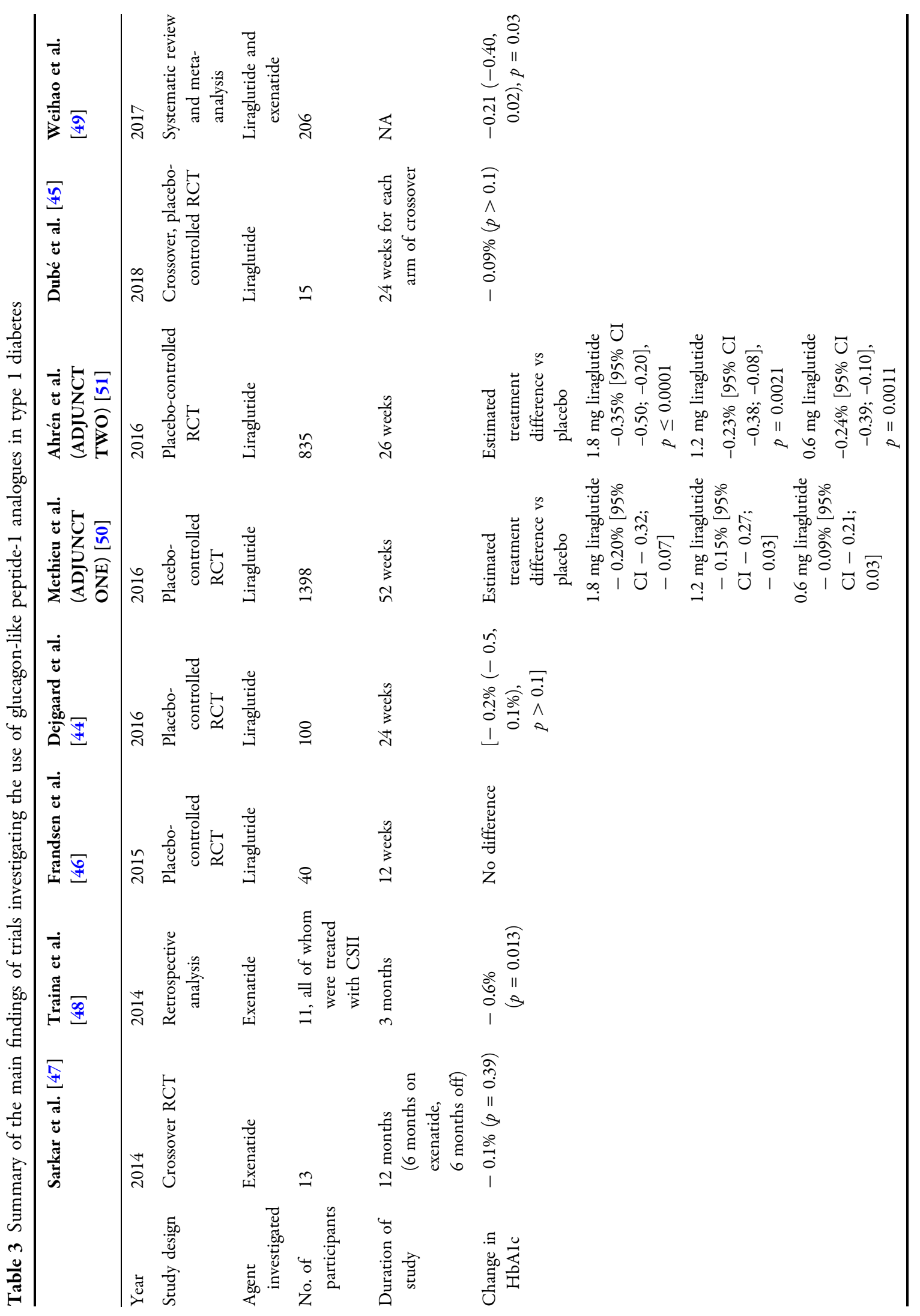




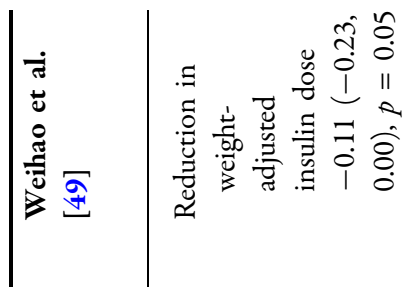

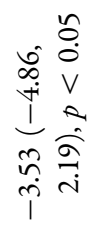

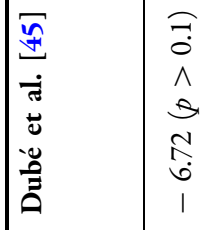

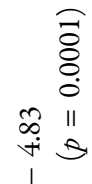

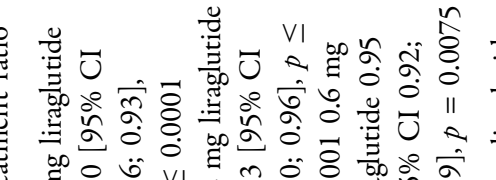

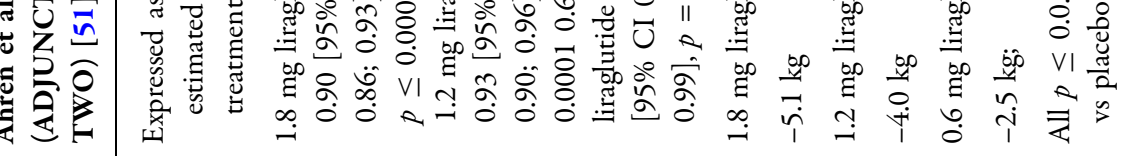

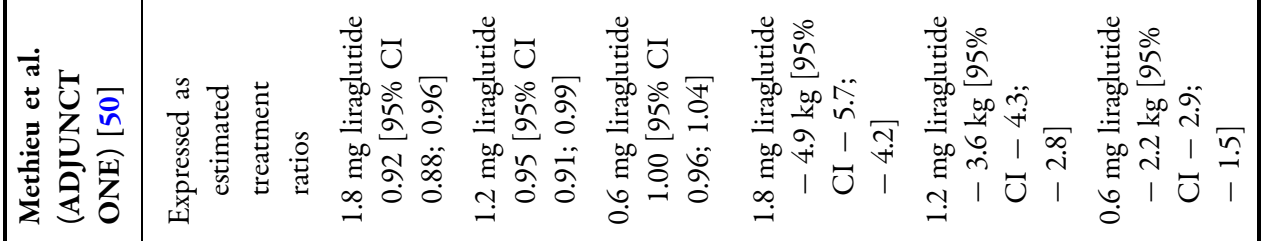

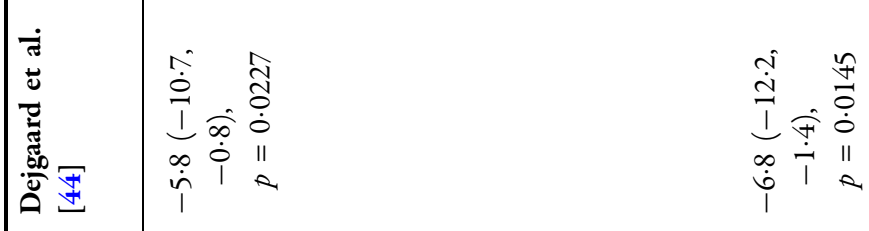

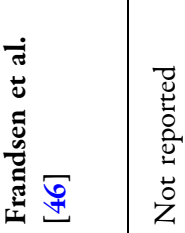

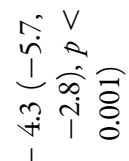

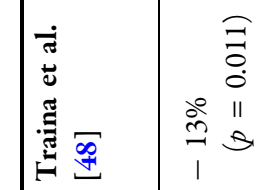

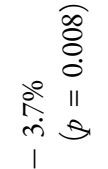

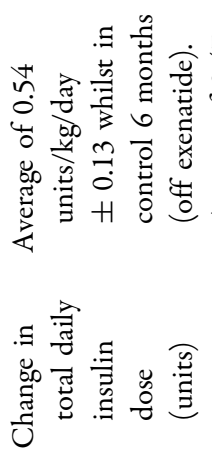

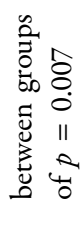

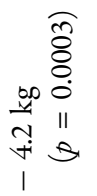

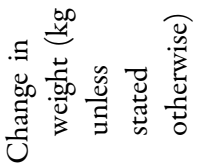

莺 


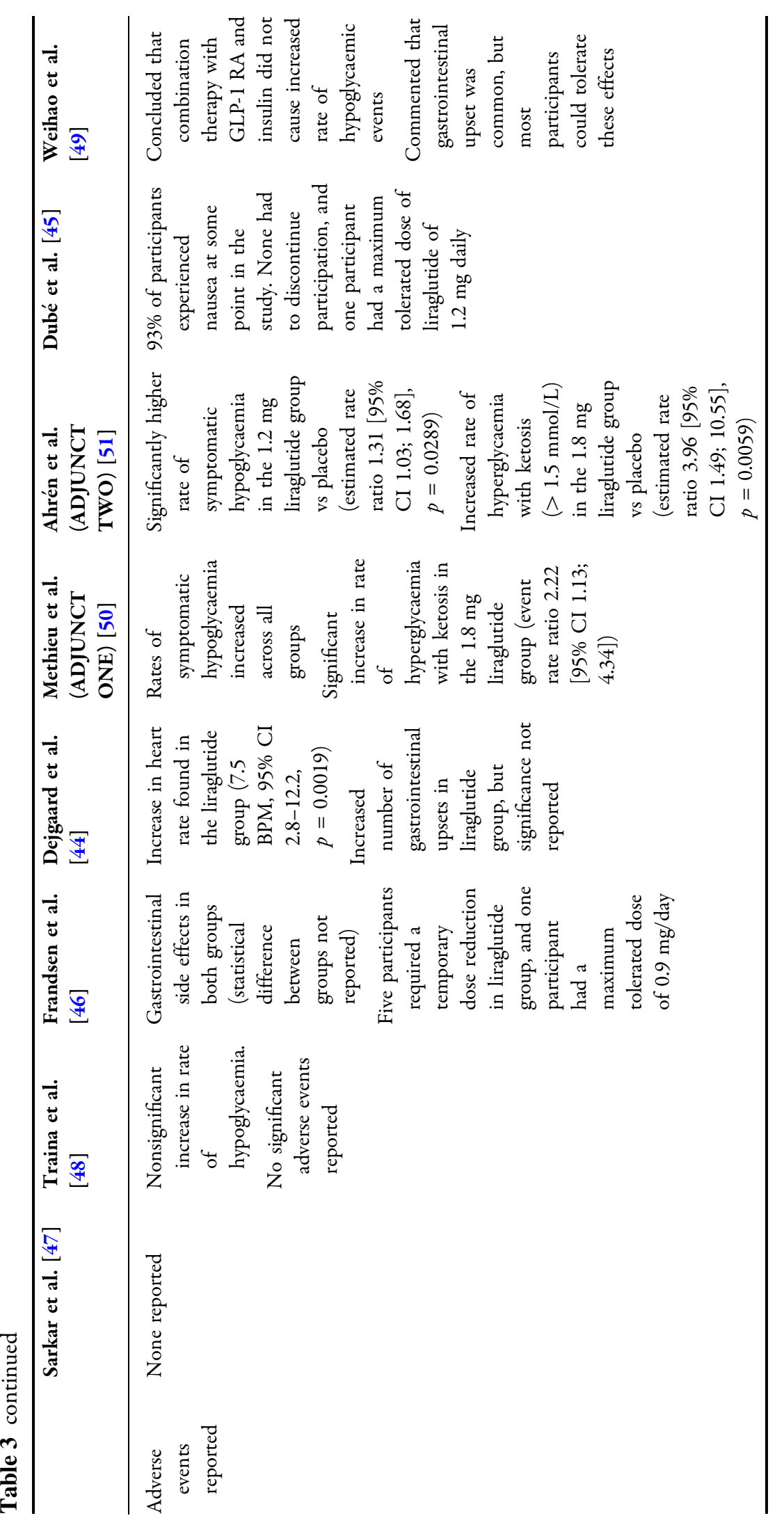


diabetes, those who suffer with the condition are rendered unable to produce this hormone in addition to insulin.

The role of amylin in satiety has become clearer recently, and it appears to have important roles in making the individual "feel full", thus controlling meal sizes, which may be partly related to the control of glucagon secretion following food consumption [53, 54]. In light of this, the role of amylin as adjuvant therapy in patients with type 1 diabetes has been explored, particularly in those who are overweight. An amylin analogue, pramlintide, is approved for use in the treatment of type 1 and type 2 diabetes in the United States, although it is not widely used worldwide.

The effect of pramlintide on HbA1c has been studied in a number of clinical trials involving patients with type 1 diabetes (Table 4). An early study found no significant decrease in $\mathrm{HbA1c}$ in those treated with pramlintide vs placebo, but insulin doses had been reduced prior to commencing therapy, which may have affected the results [55]. Further studies 26 and 52 weeks in duration found reductions in HbA1c with pramlintide vs placebo $[56,57]$. A study 52 weeks in duration that included 480 patients with type 1 diabetes showed a significant decrease of $0.27 \%$ in HbA1c upon comparing the pramlintide group with the placebo group [58]. An open-label extension of this study for a period of 1 year confirmed persistent improvements in HbA1c with continued use. Of note, the rate of those reaching a target $\mathrm{HbA1c}$ of $<7 \%$ was also increased in the pramlintide group.

Due to the pharmacodynamics of pramlintide, it could be expected that a reduction in weight would be observed in those using it in conjunction with insulin therapy. Indeed, one study found a significant decrease in weight compared to placebo over a 29-week study period $\quad(-1.3 \pm 0.3 \mathrm{~kg} \quad$ vs $\quad 1.4 \pm 0.3 \mathrm{~kg}$; $p=<0.0001$ ) [55], with similar results being seen over a 26-week study period in another study $(-1.6 \mathrm{~kg}$ placebo-adjusted, $p<0.001)$ [56]. Further work over a 52-week period confirmed a decrease in weight with pramlintide [57]. Another study in adolescents (aged 13-17 years) found significant decreases in weight over a 4-week period for pramlintide use vs placebo, indicating that these effects are applicable to a wide-ranging population [59]. Overall, there is good evidence that pramlintide reduces weight in those with type 1 diabetes.

The effects of pramlintide on insulin dosing have also been extensively evaluated. One study found a decrease in total daily insulin dose of $12 \%$ when pramlintide was used in conjunction with insulin therapy for 29 weeks. This was compared to an increase in $1 \%$ in those in the placebo arm of the study, although the significance was not reported [55]. A study in adolescents reported a significant decrease in total daily insulin dose, which was attributed to decreases in mealtime insulin requirements but no change in basal insulin dose [59]. A study 52 weeks in duration showed a small increase in total daily insulin dose in those treated with pramlintide, but this was significantly lower than the increase seen in those in the placebo arm of the trial $(2.3 \%$ vs $10.3 \%, p=0.0176$ for difference between groups) [58].

A decrease in postprandial hyperglycaemia has been hypothesised as a benefit of the use of pramlintide therapy in type 1 diabetes. One study found a decrease in mealtime insulin requirements in the pramlintide group of $28 \%$ in the first 4 weeks, but this did not alter for the rest of the study, and basal insulin requirements were unchanged [57]. This is likely due to a significant decrease in postprandial glucose in the pramlintide group as compared to baseline, which was not observed in the placebo group. Another study, which assessed the effect of pramlintide in those using closed-loop insulin systems, found significant blunting of postmeal glucose levels and prolongation of time to maximum glucose level compared to baseline after 3-4 weeks of pramlintide use [60]. Furthermore, a crossover study involving twelve patients with type 1 diabetes found a significant reduction in postprandial hyperglycaemia when pramlintide was used [61]. Other studies have confirmed decreases in postprandial glucose levels [59, 62].

Hypoglycaemia has been evaluated in a number of studies looking at the adjuvant use of pramlintide in type 1 diabetes. One study found no change in overall rates of hypoglycaemia 


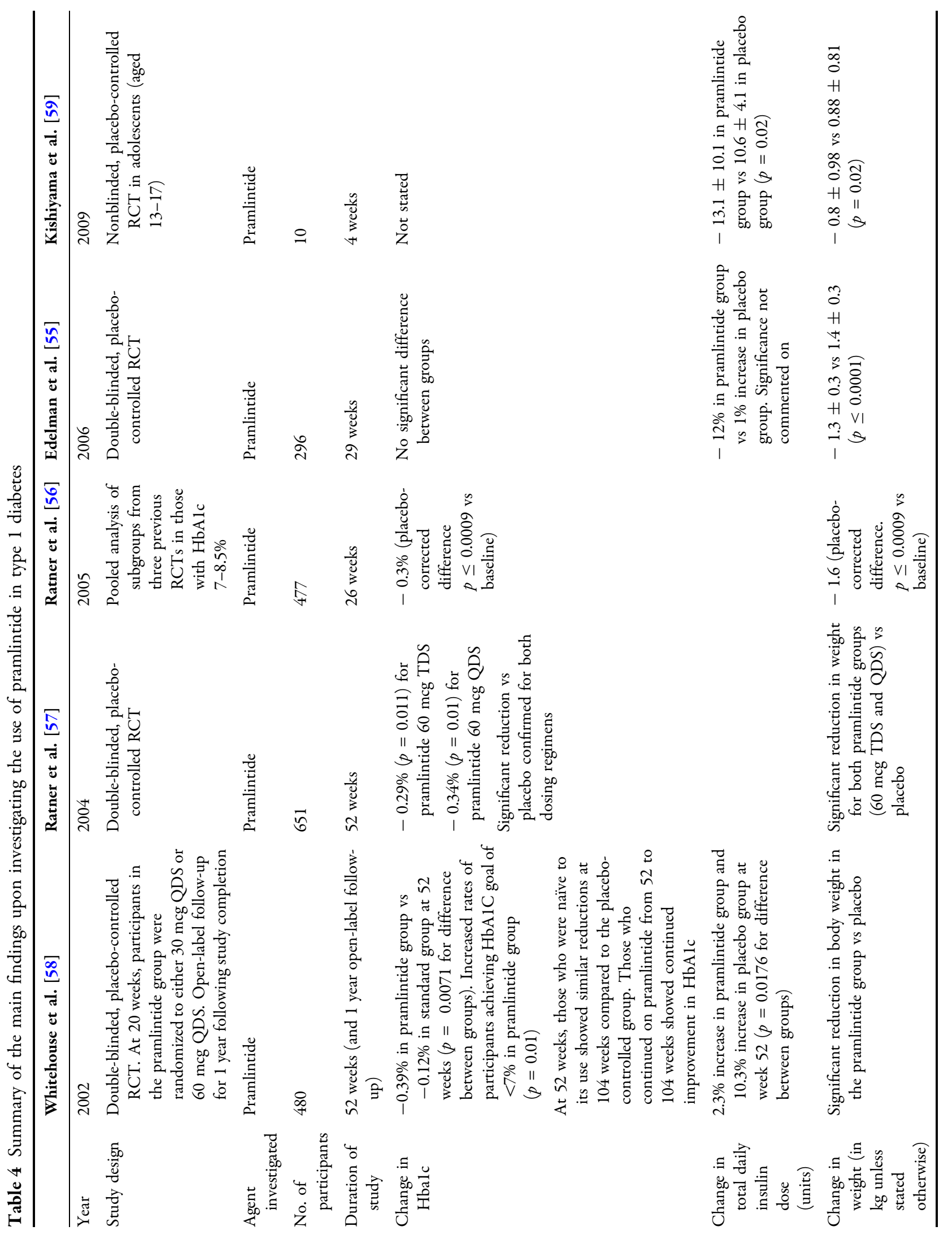




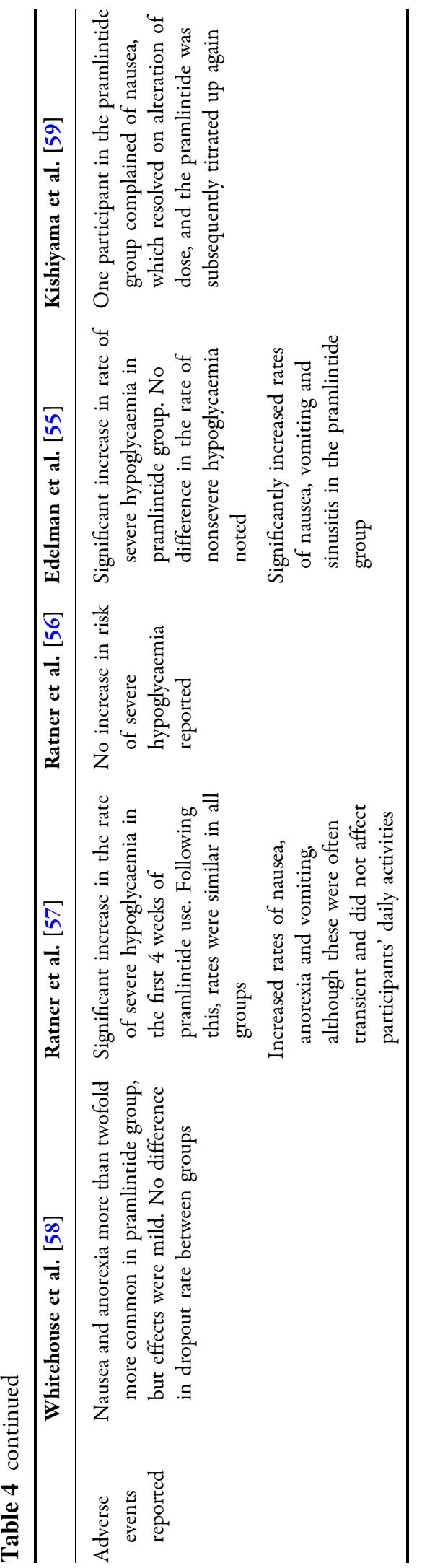

compared to placebo, but noted a significant increase in the rate of severe hypoglycaemia (event rate/patient year $0.57 \pm 0.09$ vs $0.30 \pm 0.06 ; p<0.05$ ) [55]. Further studies have not shown increased rates of severe hypoglycaemia [56, 58, 59]. Additionally, one study found an increased rate of hypoglycaemia when commencing pramlintide (first 4 weeks of study), but this reduced to a rate comparable with that in the placebo group after this period [57]. Results are therefore somewhat conflicting, but on balance it would appear that pramlintide is not associated with an increased risk of hypoglycaemia if insulin dosing is adjusted carefully (as done routinely in clinical trials) when the patient is started on this medication.

In summary, pramlintide appears to have positive effects on HbA1c and weight. Effects on total daily insulin dosing are less clear-cut, but at worst it does not appear to be inferior to placebo in this regard. The evidence of a reduction in postprandial hyperglycaemia in this class is strong and, with careful adjustment of the insulin dosing, it does not appear to be associated with an increased risk of severe hypoglycaemia.

Of note, the majority of patients with type 1 diabetes are treated with multiple daily injections of insulin, and the addition of a further three or four subcutaneous injections daily is likely a deterrent for many.

\section{DPP-4 INHIBITORS}

The use of DPP-4 inhibitors is now widespread for the treatment of type 2 diabetes, with many contributory factors leading to their popularity. Their neutral effect on weight, ease of oral administration and good tolerability are some of the factors cited as reasons for high rates of prescription. However, when investigating their use in type 1 diabetes, it is apparent that there are relatively few well-run randomized controlled trials.

A meta-analysis looking at this topic was published early in 2018 [63]. Only five trials met the inclusion criteria, which included a total of 253 patients. When one study was excluded due to a lack of HbA1c data, this glycaemic marker 
showed a nonsignificant reduction of $-0.07 \%$ (95\% CI: $-0.37 \%$ to $0.23 \%$ ).

One study looked at the effects of sitagliptin on postprandial glucose levels in those with type 1 diabetes treated with a closed-loop system. In this small study, the authors found a statistically significant decrease in postprandial glucose when sitagliptin was added, and they commented that insulin delivery was lower in the sitagliptin group [64]. No adverse events were reported by the authors, and there was no significant difference in the rate of hypoglycaemia between groups.

Despite the lack of convincing effects of these agents on $\mathrm{HbA} 1 \mathrm{c}$ in type 1 diabetes, there has been an interest in preserving $\beta$-cell function using these agents $[65,66]$. Although early results are promising, no firm conclusions can be drawn, and this remains an area for future research.

\section{CONCLUSION AND FUTURE PERSPECTIVES}

A number of studies have explored the use of adjuvant therapy in patients with T1DM, but these have been generally small, of short duration and have been primarily focussed on glycaemia, measured as the change in HbA1c. There is more to glycaemia than HbA1c, and the roles of adjuvant therapy in hypoglycaemia, glucose excursion following meals and glycaemic variability are yet to be fully investigated. Also, more attention should be given to non-glycaemia risk factors such as weight, waist circumference, blood pressure and insulin resistance markers. In contrast to T2DM studies, there is a lack of hard clinical outcome trials with different therapies in T1DM due to difficulties encountered with the funding of such work, given the relatively small number of patients with T1DM and the commercial viability of using adjuvant therapies in those patients.

Studies so far suggest that adding metformin to insulin therapy in T1DM temporarily lowers HbA1c and decreases weight and insulin requirements, but these effects are not sustained. The side-effect profile is favourable and the risks associated with this therapy are small. Therefore, metformin can be added to insulin therapy in these patients, but only short-term use is justified given current data. It remains to be seen whether intermittent treatment with metformin is superior to long-term use, which would require carefully designed studies conducted over 3-5 years.

There has been a flurry of research studies investigating SGLT2 inhibitors in T1DM, and these agents appear to show the most promise in correcting hyperglycaemia. Just as for metformin, studies investigating the effects of SGLT2 inhibitors on glycaemic measures other than $\mathrm{HbA1c}$ are generally lacking. Weight and BP reductions with SGLT2 inhibitors are additional favourable effects that may prove to reduce vascular complications and appropriate outcome studies are needed. In contrast to metformin, however, there are some safety concerns primarily related to the precipitation of DKA, although the incidence of this complication appears to vary with the agent applied. GLP-1 agonists may seem like credible partners to insulin, but studies in T1DM failed to show sizeable effects of them on glycaemia, although their role in reducing weight is unquestionable. There are concerns, based on two large multicentre RCTs, that there may be increased rates of symptomatic hypoglycaemia and hyperglycaemia with ketosis in those taking liraglutide with type 1 diabetes, and further investigation into this is required. Conclusions on the use of DPP-4 inhibitors in type 1 diabetes are difficult to draw as there have been few high-quality clinical trials examining this topic. Pramlintide has certainly shown positive effects on glycaemic control and weight, and does not appear to have a significant risk profile. The addition of multiple further injections per day may be a barrier to its use by many patients with type 1 diabetes, however.

One criticism of adjuvant treatment studies in T1DM is the assumption that T1DM patients are a homogeneous group of individuals who present similar responses to such therapies. It is likely that adjuvant therapies will work best in a particular subset of patients, so future studies should perhaps have a more focussed approach and concentrate on higher-risk groups. For 
example, overweight T1DM patients are known to have a higher risk of complications, so future adjuvant studies are needed to investigate this group of individuals. Also, studies investigating vascular surrogate markers in the higher-risk group would be of interest and would help to decide whether longer-term outcome studies using adjuvant therapies in T1DM are warranted.

It is clear that the treatment of T1DM is evolving, and restricting therapy to insulin replacement alone is an approach that is too simplistic. Future longer-term adjuvant studies on appropriate subgroups of T1DM patients and investigations of various glycaemic parameters, surrogate vascular markers and even harder clinical outcomes will help to refine our understanding of the role of such therapies in insulin-deficient states.

\section{ACKNOWLEDGEMENTS}

Funding. No funding or sponsorship was received for the publication of this article. The article processing charge was funded by the authors.

Authorship. All authors meet the International Committee of Medical Journal Editors (ICMJE) criteria for authorship of this article, take responsibility for the integrity of the work as a whole, and have given their permission for this version to be published.

Disclosures. Harriet Warnes and Rebecca Helliwell have no disclosure to declare. Sam Matthew Pearson has received fees for speaking at events organised by Novo Nordisk. Ramzi A. Ajjan has received research grants, honoraria and provided educational support and consultancy for Abbott Diabetes Care, AstraZeneca, Bayer, Boehringer Ingelheim, Bristol-Myers Squibb, Eli Lilly, GlaxoSmithKline, Merck Sharp \& Dohme, Novo Nordisk, Roche and Tadeka.

Compliance with Ethics Guidelines. The article is based on previously conducted studies and does not contain any studies with human participants or animals performed by any of the authors.

Data Availability. Data sharing is not applicable to this article, as no datasets were generated or analysed during the current study.

Open Access. This article is distributed under the terms of the Creative Commons Attribution-NonCommercial 4.0 International License (http://creativecommons.org/licenses/ by-nc/4.0/), which permits any noncommercial use, distribution, and reproduction in any medium, provided you give appropriate credit to the original author(s) and the source, provide a link to the Creative Commons license, and indicate if changes were made.

\section{REFERENCES}

1. De Ferranti SD, de Boer IH, Fonseca V, et al. Type 1 diabetes mellitus and cardiovascular disease: a scientific statement from the American Heart Association and American Diabetes Association. Diabetes Care. 2014;37(10):2843-63.

2. National Institute for Health and Care Excellence. Type 1 diabetes in adults: diagnosis and management (NICE guideline NG17). London: National Institute for Health and Care Excellence; 2015.

3. Chamberlain JJ, Kalyani RR, Leal S, et al. Treatment of type 1 diabetes: synopsis of the 2017 American Diabetes Association standards of medical care in diabetes. Ann Intern Med. 2017;167(7):493-8.

4. Nathan DM. DCCT/EDIC Research Group for the DR. The Diabetes Control and Complications Trial/ Epidemiology of Diabetes Interventions and Complications study at 30 years: overview. Diabetes Care. 2014;37(1):9-16.

5. Fullerton B, Jeitler K, Seitz M, Horvath K, Berghold A, Siebenhofer A. Intensive glucose control versus conventional glucose control for type 1 diabetes mellitus. Cochrane Database Syst Rev. 2014;(2): CD009122. https://doi.org/10.1002/14651858.CD0 09122.pub2.

6. The Diabetes Control and Complications Trial/ Epidemiology of Diabetes Interventions and Complications (DCCT/EDIC) Study Research Group. Intensive diabetes treatment and cardiovascular disease in patients with type 1 diabetes. NEJM. 2005;353:2643-53. 
7. Younk LM, Davis SN. Hypoglycaemia and vascular disease. Clin Chem. 2011;57(2):258-60.

8. King R, Ajjan R. Hypoglycaemia, thrombosis and vascular events in diabetes. Expert Rev Cardiovasc Ther. 2016;14(10):1099-101.

9. Rodrigues R, Alves de Medeiros L, Moreira Cunha L, et al. Correlations of the glycemic variability with oxidative stress and erythrocytes membrane stability in patients with type 1 diabetes under intensive treatment. Diabetes Res Clin Pract. 2018. https:// doi.org/10.1016/j.diabres.2018.01.031.

10. Nusca A, Tuccinardi D, Albano M, Cavallaro C, Ricottini E, Manfrini S, Pozzilli P, Di Sciascio G. Glucose variability in the development of cardiovascular complications in diabetes. Diabetes Metab Res Rev. 2018;20:e3047.

11. Muniyappa R, Sowers JR. Role of insulin resistance in endothelial dysfunction. Rev Endocr Metab Disord. $2013 ; 14(1): 5-12$.

12. Orchard TJ, Olson JC, Erbey JR, et al. Insulin resistance-related factors, but not glycemia, predict coronary artery disease in type 1 diabetes: 10-year follow-up data from the Pittsburgh Epidemiology of Diabetes Complications Study. Diabetes Care. 2003;26(5):1374-9.

13. Rodrigues TC, Biavatti K, Almeida FK, Gross JL. Coronary artery calcification is associated with insulin resistance index in patients with type 1 diabetes. Braz J Med Biol Res. 2010;43(11):1084-7.

14. Lee B-C, Lee J. Cellular and molecular players in adipose tissue inflammation in the development of obesity-induced insulin resistance. Biochim Biophys Acta. 2014;1842(3):446-62.

15. Conway B, Miller RG, Costacou T, et al. Temporal patterns in overweight and obesity in type 1 diabetes. Diabet Med. 2010;27(4):398-404.

16. Madej A, Ziółkowska K, Szymańska M, Jeziorny K, Mianowska B, Pietrzak I. Gender and age-dependent effect of type 1 diabetes on obesity and altered body composition in young adults. Ann Agric Environ Med. 2015;22(1):124-8.

17. Melin EO, Svensson R, Thunander M, Hillman M, Thulesius HO, Landin-Olsson M. Gender, alexithymia and physical inactivity associated with abdominal obesity in type 1 diabetes mellitus: a cross sectional study at a secondary care hospital diabetes clinic. BMC Obes. 2017;4:21.

18. Gong L, Goswami S, Giacomini KM, Altman RB, Klein TE. Metformin pathways. Pharmacogenet Genom. 2012;22(11):820-7.
19. Petrie JR, Chaturvedi N, Ford I, et al. Cardiovascular and metabolic effects of metformin in patients with type 1 diabetes (REMOVAL): a double-blind, randomised, placebo-controlled trial. Lancet Diabetes Endocrinol. 2017;5(8):597-609.

20. Khan ASA, McLoughney CR, Ahmed AB. The effect of metformin on blood glucose control in overweight patients with type 1 diabetes. Diabet Med. 2006;23(10):1079-84.

21. Zawada A, Naskret D, Burchardt P, et al. Metformin added to intensive insulin therapy improves metabolic control in patients with type 1 diabetes and excess body fat. Polish Arch Intern Med. 2018;128(5):294-300.

22. Jacobsen IB, Henriksen JE, Beck-Nielsen H. The effect of metformin in overweight patients with type 1 diabetes and poor metabolic control. Basic Clin Pharmacol Toxicol. 2009;105(3):145-9.

23. Pitocco D, Zaccardi F, Tarzia P, et al. Metformin improves endothelial function in type 1 diabetic subjects: a pilot, placebo-controlled randomized study. Diabetes Obes Metab. 2013;15(5):427-31.

24. Lund SS, Tarnow L, Astrup AS, et al. Effect of adjunct metformin treatment in patients with type1 diabetes and persistent inadequate glycaemic control: a randomized study. PLoS One. 2008;3(10):e3363.

25. Meng H, Zhang A, Liang Y, Hoa J, Zhang X, Lu J. Effect of metformin on glycaemic control in patients with type 1 diabetes: a meta-analysis of randomised controlled trials. Diabetes Metab Res Rev. 2018;34(4):e2983.

26. Ahmed FW, Rider R, Glanville M, Narayanan K, Razvi S, Weaver JU. Metformin improves circulating endothelial cells and endothelial progenitor cells in type 1 diabetes: MERIT study. Cardiovasc Diabetol. 2016;15(1):116.

27. Staels F, Moyson C, Mathieu C. Metformin as add-on to intensive insulin therapy in type 1 diabetes mellitus. Diabetes Obes Metab. 2017;19(10):1463-7.

28. Whalen K, Miller S, Onge ES. The role of sodiumglucose co-transporter 2 inhibitors in the treatment of type 2 diabetes. Clin Ther. 2015;37(6):1150-66.

29. Pieber TR, Famulla S, Eilbracht J, et al. Empagliflozin as adjunct to insulin in patients with type 1 diabetes: a 4-week, randomized, placebo-controlled trial (EASE-1). Diabetes Obes Metab. 2015;17(10):928-35.

30. Perkins BA, Cherney DZI, Partridge H. Sodium-glucose cotransporter 2 inhibition and glycemic control in type 1 diabetes: results of an 8-week open- 
label proof-of-concept trial. Diabetes Care. 2014;37(5):1480-3.

31. Tamez HE, Tamez AL, Garza LA, Hernandez MI, Polanco AC. Dapagliflozin as an adjunct therapy to insulin in the treatment of patients with type 1 diabetes mellitus. J Diabetes Metab Disord. 2015;14(1):78.

32. Sands AT, Zambrowicz BP, Rosenstock J, et al. Sotagliflozin, a dual SGLT1 and SGLT2 inhibitor, as adjunct therapy to insulin in type 1 diabetes. Diabetes Care. 2015;38(7):1181-8.

33. Garg SK, Henry RR, Banks P, Buse JB, et al. Effects of sotagliflozin added to insulin in patients with type 1 diabetes. NEJM. 2017;377(24):2337-48.

34. Henry RR, Thakkar P, Tong C, Polidori D, Alba M. Efficacy and safety of canagliflozin, a sodium-glucose cotransporter 2 inhibitor, as add-on to insulin in patients with type 1 diabetes. Diabetes Care. 2015;38(12):2258-65.

35. Dandona P, Mathieu C, Phillip M, et al. Efficacy and safety of dapagliflozin in patients with inadequately controlled type 1 diabetes (DEPICT-1): 24 week results from a multicentre, double-blind, phase 3, randomised controlled trial. Lancet Diabetes Endocrinol. 2017;5(11):864-76.

36. Pinto L, Rados D, Remonti L, Kramer C, Leitao C, Gross J. Efficacy of SGLT2 inhibitors in glycemic control, weight loss and blood pressure reduction: a systematic review and meta-analysis. Diabetol Metab Syndr. 2015;7(Suppl 1):A58.

37. Mosley JF, Smith L, Everton E, Fellner C. Sodiumglucose linked transporter 2 (SGLT2) inhibitors in the management of type- 2 diabetes: a drug class overview. Pharm Ther. 2015;40(7):451-62.

38. Chen J, Fan F, Wang JY, Long Y, Gao CL, Stanton RC, et al. The efficacy and safety of SGLT2 inhibitors for adjunctive treatment of type 1 diabetes: a systematic review and meta-analysis. Sci Rep. 2017;7:44128.

39. Yamada T, Shojima N, Noma H, Yamauchi T, Kadowaki T. Sodium-glucose co-transporter 2 (SGLT2) inhibitors as add-on therapy to insulin for type 1 diabetes mellitus: systematic review and metaanalysis of randomized controlled trials. Diabetes Obes Metab. 2018;20(7):1755-61.

40. Zinman B, Wanner C, Lachin JM, et al. Empagliflozin, cardiovascular outcomes, and mortality in type 2 diabetes. NEJM. 2015;373:2117-28.

41. Monami M, Dicembrini I, Mannucci E. Effects of SGLT2 inhibitors on mortality and cardiovascular events: a comprehensive meta-analysis of randomized controlled trials. Acta Diabetoligica. 2017;54(1):19-36.

42. Nadkarni P, Chepurny OG, Holz GG. Regulation of glucose homeostasis by GLP-1. Prog Mol Biol Transl Sci. 2014;121:23-65.

43. Frandsen CS, Dejgaard TF, Andersen HU, Holst JJ, Hartmann B, Thorsteinsson B, Madsbad S. Liraglutide as adjunct to insulin treatment in type 1 diabetes does not interfere with glycaemic recovery or gastric emptying rate during hypoglycaemia: a randomized, placebo-controlled, double-blind, parallel-group study. Diabetes Obes Metab. 2017;19(6):773-82.

44. Dejgaard TF, Frandsen CS, Hansen TS, et al. Efficacy and safety of liraglutide for overweight adult patients with type 1 diabetes and insufficient glycaemic control (Lira-1): a randomised, doubleblind, placebo-controlled trial. Lancet Diabetes Endocrinol. 2016;4(3):221-32.

45. Dubé M-C, D’Amours M, Weisnagel SJ. Beyond glycaemic control: a cross-over, double-blinded, 24-week intervention with liraglutide in type 1 diabetes. Diabetes Obes Metab. 2018;20(1):178-84.

46. Frandsen CS, Dejgaard TF, Holst JJ, Andersen HU, Thorsteinsson B, Madsbad S. Twelve-week treatment with liraglutide as add-on to insulin in normal-weight patients with poorly controlled type 1 diabetes: a randomized, placebo-controlled, doubleblind parallel study. Diabetes Care. 2015;38(12):2250-7.

47. Sarkar G, Alattar M, Brown RJ, Quon MJ, Harlan DM, Rother KI. Exenatide treatment for 6 months improves insulin sensitivity in adults with type 1 diabetes. Diabetes Care. 2014;37(3):666-70.

48. Traina AN, Lull ME, Hui AC, Zahorian TM, LyonsPatterson J. Once-weekly exenatide as adjunct treatment of type 1 diabetes mellitus in patients receiving continuous subcutaneous insulin infusion therapy. Can J Diabetes. 2014;38(4):269-72.

49. Weihao W, Hongyan L, Shumin X, Shuaihui L, Xin L, Pei Y. Effects of insulin plus glucagon-like peptide-1 receptor agonists (GLP-1RAs) in treating type 1 diabetes mellitus: a systematic review and metaanalysis. Diabetes Therapy. 2017;8:727.

50. Mathieu C, Zinman B, Hemmingsson JU, Woo V, Colman $\mathrm{P}$, Christiansen $\mathrm{E}$, Linder $\mathrm{M}$, Bode $\mathrm{B}$, ADJUNCT ONE Investigators. Efficacy and safety of liraglutide added to insulin treatment in type 1 diabetes: the ADJUNCT ONE treat-to-target randomized trial. Diabetes Care. 2016;39(10):1702-10.

51. Ahrén B, Hirsch IB, Pieber TR, Mathieu C, GómezPeralta F, Hansen TK, Philotheou A, Birch S, 
Christiansen E, Jensen TJ, Buse JB, ADJUNCT TWO Investigators. Efficacy and safety of liraglutide added to capped insulin treatment in subjects with type 1 diabetes: the ADJUNCT TWO randomized trial. Diabetes Care. 2016;39(10):1693-701.

52. Hartter E, Svoboda T, Ludvik B, Schuller M, Lell B, Kuenburg E. Basal and stimulated plasma levels of pancreatic amylin indicate its co-secretion with insulin in humans. Diabetologia. 1991;34:52-4.

53. Geary N. A new way of looking at eating. Am J Physiol Regul Integr Comp Physiol. 2005;288(6):R1444-6.

54. Lutz TA. Amylinergic control of food intake. Physiol Behav. 2005;89(4):465-71.

55. Edelman S, Garg S, Frias J, et al. A double-blind, placebo-controlled trial assessing pramlintide treatment in the setting of intensive insulin therapy in type 1 diabetes. Diabetes Care. 2006;29(10):2189.

56. Ratner R, Whitehouse F, Fineman MS, Strobel S, Shen L, Maggs DG, Kolterman OG, Weyer C. Adjunctive therapy with pramlintide lowers HbA1c without concomitant weight gain and increased risk of severe hypoglycemia in patients with type 1 diabetes approaching glycemic targets. Exp Clin Endocrinol Diabetes. 2005;113(4):199-204.

57. Ratner RE, Dickey R, Fineman M, Maggs DG, Shen L, Strobel SA, Weyer C, Kolterman OG. Amylin replacement with pramlintide as an adjunct to insulin therapy improves long-term glycaemic and weight control in type 1 diabetes mellitus: a 1-year, randomized controlled trial. Diabet Med. 2004;21(11):1204-12.

58. Whitehouse F, Kruger DF, Fineman M, Shen L, Ruggles JA, Maggs DG, Weyer C, Kolterman OG. A randomized study and open-label extension evaluating the long-term efficacy of pramlintide as an adjunct to insulin therapy in type 1 diabetes. Diabetes Care. 2002;25(4):724-30.

59. Kishiyama CM, Burdick PL, Cobry EC, Gage VL, Messer LH, McFann K, Chase HP. A pilot trial of pramlintide home usage in adolescents with type 1 diabetes. Pediatrics. 2009;124(5):1344-7.
60. Sherr JL, Patel NS, Michaud CI, Palau-Collazo MM, Van Name MA, Tamborlane WV, Cengiz E, Carria LR, Tichy EM, Weinzimer SA. Mitigating meal-related glycemic excursions in an insulin-sparing manner during closed-loop insulin delivery: the beneficial effects of adjunctive pramlintide and liraglutide. Diabetes Care. 2016;39(7):1127-34.

61. Hinshaw L, Schiavon M, Dadlani V, Mallad A, Dalla Man C, Bharucha A, Basu R, Geske JR, Carter RE, Cobelli C, Basu A, Kudva YC. Effect of pramlintide on postprandial glucose fluxes in type 1 diabetes. J Clin Endocrinol Metab. 2016;101(5):1954-62.

62. Ceriello A, Piconi L, Quagliaro L, Wang Y, Schnabel CA, Ruggles JA, Gloster MA, Maggs DG, Weyer C. Effects of pramlintide on postprandial glucose excursions and measures of oxidative stress in patients with type 1 diabetes. Diabetes Care. 2005;28(3):632-7.

63. Wang Q, Long $\mathrm{M}, \mathrm{Qu} \mathrm{H}$, Shen $\mathrm{R}$, Zhang $\mathrm{R}, \mathrm{Xu}$ J, Xiong X, Wang H, Zheng H. DPP-4 inhibitors as treatments for type 1 diabetes mellitus: a systematic review and meta-analysis. J Diabetes Res. 2018;8(2018):5308582.

64. Underland LJ, Ilkowitz JT, Katikaneni R, Dowd A, Heptulla RA. Use of sitagliptin with closed-loop technology to decrease postprandial blood glucose in type 1 diabetes. J Diabetes Sci Technol. 2017;11(3):602-10.

65. Awata T, Shimada A, Maruyama T, Oikawa Y, Yasukawa N, Kurihara S, Miyashita Y, Hatano M, Ikegami Y, Matsuda M, Niwa M, Kazama Y, Tanaka S, Kobayashi T. Possible long-term efficacy of sitagliptin, a dipeptidyl peptidase-4 inhibitor, for slowly progressive type 1 diabetes (SPIDDM) in the stage of non-insulin-dependency: an open-label randomized controlled pilot trial (SPAN-S). Diabetes Ther. 2017;8(5):1123-34.

66. Ding L, Gysemans CA, Stangé G, Heremans Y, Yuchi Y, Takiishi T, Korf H, Chintinne M, Carr RD, Heimberg H, Pipeleers D, Mathieu C. Combining MK626, a novel DPP-4 inhibitor, and low-dose monoclonal CD3 antibody for stable remission of new-onset diabetes in mice. PLoS One. 2014;9(9):e107935. 